\title{
A inserção do profissional de educação física na atenção primária à saúde e os desafios em sua formação
}

FALCI, D.M.; BELISÁRIO, S.A. The position of physical education professionals within primary healthcare and the challenges in their training. Interface (Botucatu), v.17, n.47, p.885-99, out./dez. 2013.

The presence of physical education professionals within Family Health Support Centers has shown the weakness of their training regarding primary care. The aim of this article was to analyze these professionals' training to work in primary care, in Minas Gerais. This was a qualitative exploratory investigation, of case study type. Data were collected through focus groups. The results showed that their presence is positive for the profession and for the healthcare services, but indicated that there are some difficulties. Among these, undergraduate training was mentioned as insufficient for working in primary care. Postgraduate training was identified as one strategy for minimizing this insufficiency.

Keywords: Physical education and training. Primary healthcare. Support Center for Family Health. Human resources formation. Family health.
A inserção do profissional de Educação Física no Núcleo de Apoio à Saúde da Família evidenciou a fragilidade de sua formação para a atenção primária.

Objetivou-se analisar sua formação para a inserção neste campo, em Minas Gerais. Trata-se de pesquisa qualitativa e exploratória, do tipo estudo de caso. Os dados foram obtidos utilizando-se grupos focais. Os resultados apontaram essa inserção como positiva para a profissão e para os serviços de saúde, porém indicaram algumas dificuldades, dentre elas, a graduação foi mencionada como insuficiente para atuar na atenção primária. A pós-graduação foi identificada como uma das estratégias para minimizar essa insuficiência.

Palavras-chave: Educação física e treinamento. Atenção primária à saúde. Núcleo de Apoio à Saúde da Família. Formação de recursos humanos. Saúde da Família.

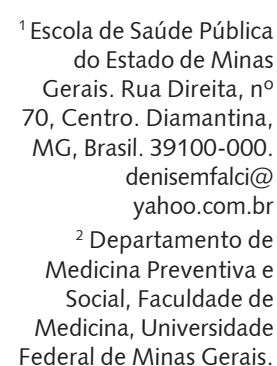

${ }^{1}$ Escola de Saúde Pública Gerais. Rua Direita, $n^{\circ}$ 70, Centro. Diamantina denisemfalci@ yahoo.com.br Departamento de Social, Faculdade de Federal de Minas Gerais. 


\section{Introdução}

A Saúde da Família (SF) é a estratégia prioritária para a expansão e consolidação da Atenção Primária à Saúde (APS) (Brasil, 2011b), sendo operacionalizada mediante a implantação de equipes multiprofissionais compostas por médicos, enfermeiros, agentes comunitários de saúde e auxiliares de enfermagem.

Objetivando apoiar essa estratégia na rede de serviços e ampliar a abrangência e o escopo das ações das equipes, foi criado o Núcleo de Apoio à Saúde da Família (NASF) pela Portaria 154, de 24 de janeiro de 2008. Desde então, outros profissionais foram formalmente inseridos na APS, dentre eles o Profissional de Educação Física (PEF) (Brasil, 2008).

A partir do reconhecimento da importância da atividade física para a promoção da saúde e prevenção de doenças crônico-degenerativas, importantes causas de morbimortalidade no Brasil, houve, ainda que de forma incipiente, o aumento da demanda pelos PEF na APS, o que evidenciou a fragilidade de sua formação para a área (Bonfim, Costa, Monteiro, 2012; Pasquim, 2010).

$\mathrm{Na}$ tentativa de tornar a formação dos profissionais de saúde consonante aos princípios e diretrizes do Sistema Único de Saúde (SUS), o Ministério da Saúde e da Educação vem desenvolvendo e apoiando ações na graduação e na pós-graduação, destacando-se a homologação, em 2004, das Diretrizes Curriculares Nacionais (DCN) do curso de graduação em Educação Física (EF). Essas diretrizes preveem formação de profissionais capazes de avaliar a realidade social e nela intervir por meio das manifestações e expressões do movimento humano (Brasil, 2004).

Nesse contexto, algumas Instituições de Ensino Superior (IES) promovem mudanças curriculares para aproximar a formação das diretrizes. Essas mudanças, ainda insuficientes, tornam necessária a formação pós-graduada para minimizar essa deficiência (Costa et al., 2012; Anjos, Duarte, 2009; Brugnerotto, Simões, 2009).

Quanto à pós-graduação, destaca-se, aqui, o Curso de Especialização em Atenção Básica em Saúde da Família da Universidade Federal de Minas Gerais (CEABSF/UFMG), gerenciado pelo Núcleo de Educação em Saúde Coletiva (NESCON), o qual é ofertado na modalidade a distância e em escala. Esse curso lato sensu foi implantado em 2008, para atender a uma demanda do Ministério da Saúde de formar profissionais (médicos, enfermeiros e cirurgiões-dentistas) formalmente vinculados à SF de Minas Gerais.

A parceria do CEABSF com o Conselho Regional de Educação Física da $6^{a}$ região/ Minas Gerais (CREF6/MG), a Escola de Educação Física, Fisioterapia e Terapia Ocupacional (EEFFTO)/UFMG e o Laboratório do Movimento/UFMG resultou em uma oferta especial dirigida ao PEF: a turma Épsilon. Nesse processo, o Laboratório do Movimento intermediou o vínculo entre o NESCON e a EEFFTO, a qual assumiu o CEABSF como projeto institucional e elaborou conteúdos específicos à EF. Já o CREF6/ MG publicou esse material, divulgou a especialização entre seus membros, e colaborou operacionalmente para os encontros presenciais. Essa parceria resultou em uma experiência pioneira para a formação do PEF.

Assim, este artigo objetivou analisar a formação do PEF para sua inserção na APS, em Minas Gerais, a partir da visão de diferentes atores envolvidos no processo.

\section{Método}

Trata-se de pesquisa de abordagem qualitativa e exploratória, do tipo estudo de caso. Conforme critérios descritos por Yin (2005), esta pesquisa é classificada como estudo de caso, visto que se pretendeu responder questões do tipo "como" e "por que", e por ter se trabalhado sobre eventos contemporâneos, em situações que os comportamentos não podem ser manipulados.

Para a coleta de dados, utilizou-se de grupo focal e entrevista semiestruturada. Foram realizados dois grupos focais, compostos por PEF, alunos do CEABSF, sendo constituídos por sete e oito integrantes - números coerentes com o sugerido pela literatura (Carlini-Cotrim, 1996). Os alunos foram selecionados segundo os critérios: possuir experiência na APS e estar em fase final do curso. 
Os grupos foram realizados na Faculdade de Medicina da UFMG em um único encontro, com duração média de uma hora e 15 minutos.

As entrevistas semiestruturadas foram realizadas individualmente, com duração média de trinta minutos, com os seguintes informantes-chave: representante da coordenação do CEABSF; representante da coordenação do curso de graduação em EF/UFMG - Bacharelado; e representante da presidência do CREF6/MG.

A coleta de dados se deu no primeiro semestre de 2012, sendo as falas gravadas em áudio para posterior transcrição. Os grupos focais e entrevistas semiestruturadas foram guiados por roteiros específicos que abordavam os seguintes temas: inserção do PEF na APS; formação do PEF para a APS, e dificuldades para essa inserção.

A análise dos dados se deu pela técnica de Análise de Conteúdo proposta por Bardin (2008). Após a leitura exaustiva das entrevistas transcritas, houve a sua codificação e posterior categorização, resultando nas categorias: Inserção na APS; Formação para a APS; Dificuldades.

Esta pesquisa foi aprovada pelo Comitê de Ética em Pesquisa da UFMG. Todos os entrevistados assinaram o Termo de Consentimento Livre e Esclarecido, garantindo a participação voluntária e anônima.

\section{Resultados e discussão}

\section{Inserção na APS}

Os entrevistados consideraram o reconhecimento do PEF enquanto profissional da saúde como um ganho da profissão, que favoreceu a ampliação do seu mercado de trabalho e levou a reflexões em relação à sua formação.

Para eles, a inserção do PEF na APS representou: quebra de paradigma, reforço à necessidade de mudanças na formação, progresso para a profissão e contribuição aos serviços de saúde. Essa última foi relacionada à possibilidade de o mesmo gerar maior qualidade nas ações que envolvem a atividade física e de ampliar seu escopo no que se refere à promoção e proteção à saúde. Entretanto, relataram que o PEF ainda não foi incluído, de fato, neste campo.

“[...] esse paradigma que está sendo mudado é o mesmo de [...] quando o desporto passou a ter uma legislação específica no Brasil, e aí fez com que o Brasil pudesse [...] deslanchar bastante [no desporto] [...]". (E1)

“[...] por enquanto esse profissional ele só foi inserido, ele não foi incluído no sistema, mas é o caminho que a gente tem que traçar pra ser incluído definitivamente [...]". (GF1)

Loch et al. (2011) também acreditam que a inserção do PEF na APS contribuiu para a profissão e o serviço, já que possibilitou interação com outros profissionais e incentivou um estilo de vida ativo na população. Em Pedrosa e Leal (2012), membros de categorias tradicionais da SF pontuaram que a inserção do PEF no NASF é uma oportunidade de uma maior interdisciplinaridade na promoção da saúde e redução da demanda dos usuários aos serviços do SUS de maior complexidade.

Estar no NASF foi percebido como um momento em que o PEF foi alçado à mesma condição de profissões da saúde mais consolidadas, e como uma oportunidade de maior reconhecimento pela população, este apontado como um fator motivador.

“[...] a profissão já é mais reconhecida pela população por não ser mais aquela que explica exercícios físicos, ela já está sendo vista como uma profissão que pode oferecer qualidade de vida [...]". (E1) 
"[...] o reconhecimento da população [...] é que faz a gente ser criativo pra montar o material que a gente não tem, [...] percorrer vários bairros [...]". (GF2)

Os entrevistados acreditam que a inserção do PEF na APS se deu em decorrência da maior incidência das doenças crônicas não transmissíveis e do incentivo da política de saúde. Contudo, ressaltou-se que esta inserção ainda é dependente do apoio dos gestores de saúde.

“[...] na visão do NASF, você tem vários profissionais que o gestor municipal pode escolher, se escolhe uma visão de prevenção, ele vai ter preferência por alguns profissionais, se escolhe uma visão de promoção, ele vai ter tendência a escolher outros profissionais [...]". (GF1)

Para Loch e Florindo (2012), a inserção do PEF no NASF por si só representa, além de uma importante conquista da profissão, o reconhecimento da EF enquanto profissão da saúde, e da atividade física enquanto pauta da Saúde Pública.

A promoção da saúde e a prevenção de doenças foram mencionadas como foco do trabalho do PEF na APS. Entretanto, reconheceram que sua atuação se dá por meio das atividades físicas, desportivas e recreativas.

"[...] o Profissional de Educação Física tem a cara do NASF porque o NASF é promoção da saúde, NASF é grupo, é grupo operativo [...]". (GF2)

"[...] pras atividades físicas, desportivas, recreativas em geral, é que o Profissional de Educação Física tem de se inserir na área de saúde". (E1)

Segundo Pedrosa e Leal (2012), pensar a atuação do PEF nas ações voltadas à promoção da saúde implica análise da sua formação e maior aproximação com os profissionais que já atuam no setor. Médicos e enfermeiros, neste mesmo estudo, se disseram favoráveis à inserção do PEF nos NASF, porém consideraram necessário repensar a sua formação para que suas ações sejam efetivas neste contexto.

A ideia de que a promoção da saúde deve ser uma prática desenvolvida por todos os profissionais da saúde foi convergente entre os membros dos grupos focais. Contudo, afirmou-se que a prescrição da atividade física deve ser prerrogativa do PEF.

"[...] antigamente [...] qualquer pessoa podia prescrever atividade física, [...] e, hoje, dentro da área da saúde está tendo outra conotação específica profissional [...]". (GF1)

Loch e Florindo (2012) defendem que a EF tem um papel central na prática da atividade física, porém acreditam que seria irresponsabilidade não admitir a colaboração de outras categorias profissionais. Hallal (2011) vai além ao afirmar que ações que incentivem hábitos fisicamente ativos na população devem ser desenvolvidas por meio de uma articulação multissetorial.

Alguns autores acreditam que compete ao PEF facilitar a prática de atividade física e monitorá-la, na maioria das vezes, por meio de grupos específicos (Souza, Loch, 2011; Brugnerotto, Simões, 2009; Freitas, 2007). Freitas (2007) também afirma que o PEF, na APS, deve direcionar sua prática para o aspecto educativo, e não apenas reproduzir a atividade física, pois ações com essa concepção ampliam as formas de atuação e de concepção da saúde na área da EF e vice-versa.

Para os depoentes, ao contrário de outros profissionais que são relacionados à doença, os usuários têm, no PEF, uma referência de bem-estar.

“[...] o Profissional de Educação Física que está no NASF representa alegria, descontração, um renovar, porque os usuários não vão mais na busca da cura da doença, então quando fala pro doutor, pra enfermeira, [...] tem um referencial de busca [...] pra sua cura, ao mesmo 
tempo, recorre ao professor de Educação Física no prazer, [...] a gente entra na parte psicossomática [...]". (GF2)

A inserção do PEF na APS deve incentivar hábitos saudáveis através de diferentes estratégias. Entretanto, tais estratégias devem ser pensadas e discutidas com a comunidade, chamando atenção para o cotidiano em que vivem e para os valores que priorizam (Freitas, 2007).

Apesar de os entrevistados alegarem que sempre estiveram envolvidos com a saúde, reconhecem que este envolvimento não se dava no contexto da APS e que estavam despreparados para ingressar neste campo.

“[...] a Educação Física sempre mexeu com a saúde, não na perspectiva da saúde da atenção primária $[\ldots] " .$. (GF1)

“[...] a gente não estava preparado pra isso, [...] falar que eu ia trabalhar com a saúde primária, que eu ia tá lá nos PSF, [...] não imaginava que isso fosse acontecer tão cedo, apesar de que eu sabia que isso um dia ia acontecer [...]". (GF2)

\section{Dificuldades}

A falta de conhecimento ou reconhecimento, pela equipe de saúde e população, quanto ao seu papel e importância na APS foram algumas das dificuldades apontadas nos grupos focais.

“[...] quando a equipe da Saúde da Família direcionava o usuário pra gente, eles chegavam até a mim como se eu fosse uma fisioterapeuta, [...] então eu tive que mostrar que eu era uma Profissional de Educação Física, [...] tive que mostrar a importância do profissional dentro da saúde primária $[\ldots] "$ ". (GF2)

“[...] o usuário tá lá, o médico é doutor, a enfermeira é doutora [...] e nós somos os professores, [...] realmente existe uma diferenciação, [...] a pessoa [...] vê [...] o Profissional da Educação Física talvez [como] o que gosta da brincadeira, [...] que não entende muito $[\ldots]^{\prime \prime} .(\mathrm{GF} 2)$

Para Silva e Trad (2005), as relações entre profissionais promovem um trabalho integrado a partir do momento em que conhecem as competências e a importância de cada profissional para a atenção integral à saúde.

Os depoentes acreditam que o não-reconhecimento do PEF por outros profissionais da saúde gera uma frágil relação no trabalho interprofissional. Embora tenham interesse em atuar em equipe, declararam ter dificuldade em se integrar à mesma, reconhecendo que parte desta dificuldade se deve ao próprio PEF.

“[...] o maior desafio [...] na atenção primária é o trabalho multidisciplinar, é a integração entre os profissionais. Às vezes [...] quero desenvolver determinado grupo operativo com outro profissional e [...] não consigo [...]". (GF2)

"[...] ainda existe uma grande dificuldade de relacionamento interpessoal, inclusive nós, Profissional de Educação Física, com as outras profissões [...]". (GF2)

Loch e Florindo (2012) ressaltam que esta dificuldade também é enfrentada por outras categorias profissionais e acreditam que, para confrontá-la, seja necessário que os envolvidos estejam abertos a compartilhar conhecimentos. 
O trabalho em equipe é apontado como uma oportunidade de troca de informações e uma possibilidade de desenvolver trabalhos coletivos (Souza, Loch, 2011). Além disso, Freitas (2007) acredita que a complexidade dos problemas na APS exige que se tenham diferentes profissionais atuando juntos, e que o envolvimento do PEF com os mesmos traz novos elementos para se discutir saúde na área da EF.

Para os entrevistados, esta dificuldade de relacionamento está atrelada à ideia comum, entre os demais profissionais, de que os PEF trabalham de forma isolada, e às expectativas específicas que os membros do serviço e a própria comunidade têm quanto ao seu trabalho.

"[...] a visão que eles ainda têm do profissional [é de] trabalho que fica isolado [...]". (GF1)

“[...] a gente chega com uma proposta, e a demanda do lugar é outra, eles esperam que o Profissional de Educação Física vá atuar de uma maneira específica ali, [...] às vezes nem recebem bem o que você quer propor, [...] depende da visão do outro, às vezes de uma gerência do centro de saúde, de uma equipe, de um grupo, da comunidade [...]". (GF1)

Freitas (2007) afirma que é necessário considerar os objetivos do PEF, do serviço e do usuário, sendo igualmente importante que o PEF saiba adaptar esses elementos à sua prática, sem se descaracterizar em função dos interesses institucionais.

Outra dificuldade apontada foi a falta de apoio do serviço aos PEF, o que confere, aos mesmos, um sentimento de discriminação.

“[...] eu pude perceber, logo que entrei no NASF, a gente não teve muito apoio, então eu senti um pouco discriminada $[\ldots]^{\prime \prime}$. (GF2)

Loch et al. (2011) afirmam que esse aparente desinteresse do serviço pelo PEF pode estar relacionado à concepção médico-curativista, que parece ainda ser hegemônica, não se sabendo até que ponto o serviço de saúde está aberto a essa categoria profissional. Uma forma evidenciada por Souza e Loch (2011) para minimizar a resistência de outros profissionais ao trabalho do PEF foi a capacitação entre os profissionais das unidades básicas de saúde.

A indefinição das atribuições dos PEF, por parte do serviço, e a inexistência de um plano de metas para direcionar o seu trabalho na APS foram também apontadas como dificuldades. Em alguns casos, tal situação fez com que o profissional desenvolvesse sua própria sistemática de trabalho.

“[...] a gente caiu meio de paraquedas [...], não tinha mesmo uma questão burocrática de serviço [...] às vezes o coordenador não sabia: ah... começa a visitar as unidades aí. [...] não tem uma meta direito, quantos você tem que atender, porque e quem, então fica tudo meio solto $[\ldots] " . .(G F 2)$

"A gente criou um modelo, uma forma de trabalhar, [...] buscando a portaria, buscando artigos, [...] a partir do que a gente entendia [...]". (GF2)

"[...] no meu serviço a gente acaba fazendo um plano de ação e metas no início do ano, colocando as metas que a gente quer atingir [...]". (GF2)

Os entrevistados afirmaram que o PEF ainda necessita conquistar espaço na APS, o que acontecerá por meio do conhecimento sobre o serviço de saúde e sobre seu papel neste ambiente.

"[...] ele precisa mais trabalhar na organização do serviço, ele tem que saber como ele se insere [...] é um espaço que ele tem que conquistar, então para conquistar ele tem que conquistar a linguagem, conteúdo, aprender a fazer planejamento [...]" (E2) 
Dado semelhante foi encontrado por Santos e Benedetti (2012), que relacionaram a dificuldade do PEF em definir seu papel e competências para o SUS à sua pouca experiência na saúde pública. Freitas (2007) ressaltou que o conhecimento prévio do sistema de saúde e do serviço facilita o reconhecimento do próprio profissional nesse contexto, ajudando-o a direcionar melhor as suas ações.

A infraestrutura inadequada, nas unidades, para o desenvolvimento satisfatório das ações de saúde foi outra dificuldade destacada.

“[...] a unidade de saúde não estava preparada pra receber essa equipe nova, não tinha estrutura e como não tem ainda, muitas vezes, um local pra tá atuando [...]". (GF2)

Resultado semelhante foi observado por Souza e Loch (2011), em que os PEF entrevistados mencionaram o espaço inadequado como um importante desafio ao seu trabalho. Diante disso, o Ministério da Saúde instituiu o Programa Academia da Saúde em 2011, com o objetivo de criar espaços adequados a atividades de promoção da saúde, dentre elas a prática da atividade física. Este programa prevê a implantação de polos com infraestrutura, equipamentos e quadro de pessoal qualificado para a orientação de modos de vida saudáveis (Brasil, 2011a).

A dificuldade em atender a um grande número de equipes de SF por NASF também foi ressaltada. A demanda elevada e o número reduzido de PEF vinculados ao NASF foram mencionados como fatores negativos na busca pela qualidade do cuidado nas comunidades atendidas.

“[...] a gente tem 32 unidades de saúde e só um NASF. Eu não dou conta de atender todo mundo, eu atendo menos da metade, e a realidade que a gente vê é que nas unidades que não têm o Profissional de Educação Física os enfermeiros, os agentes de saúde fazem atividade física semanalmente, então a gente vê o que não era para estar acontecendo [...]". (GF2)

“[...] espero que [...] o Profissional de Educação Física, ele passe a atender menos unidades, ele tenha um contato maior com os grupos de atividade física, [...] ou que [...] seja criado [...] o Profissional de Educação Física [...] por PSF [...]". (GF2)

Este fato foi evidenciado por Santos e Benedetti (2012), ao afirmarem que, em 2011, o Brasil contava, em média, com 0,69 PEF por cem mil habitantes cobertos pela SF, indicando uma baixa representação deste profissional. Acreditam que, para a melhora dessa relação, é necessário investimento político e acadêmico para a definição de estratégias que contribuam para a integração do PEF no SUS. Contudo, entre as 13 profissões previstas para o NASF, o PEF foi a quinta categoria mais recrutada para este serviço, estando presente em 49,2\% das equipes do NASF, podendo ser ainda maior em alguns estados.

A falta de acesso ou o acesso restrito aos prontuários foi apontado como outro fator dificultador da troca de informações entre os membros da equipe. Esse acesso possibilitaria ao PEF tanto conhecer o histórico do usuário e sua relação com a unidade, como divulgar seu trabalho na equipe.

“[...] o acesso ao prontuário que alguns profissionais têm, e nós não, [...] prejudica também a questão do trabalho em rede, [...] se nós tivéssemos um acesso maior [...] talvez nós conseguíssemos mostrar um pouco do que a gente faz, [...] como nós estamos contribuindo com o serviço $[\ldots]^{\prime \prime}$. (GF1)

Por fim, todos os sujeitos desta pesquisa apontaram a insuficiente formação do PEF para a APS como uma importante dificuldade. 


\section{Formação para APS}

No que tange, especialmente, a esta categoria, os resultados demonstraram convergência de opiniões entre os diferentes atores abordados: profissionais/alunos do CEABSF e dirigentes, educacional e corporativo. Tal fato pode ser evidenciado por algumas falas expostas que se associam.

\section{Formação inicial}

Para os entrevistados, a formação do PEF ainda é focada no treinamento esportivo, mas acreditam que a APS deve ser a área prioritária, já que é preferencialmente neste nível que deve ocorrer o cuidado inicial.

“[...] a gente vem percebendo que a área prioritária é a atenção primária, que ela vai ser a possibilidade, pra atuação nas outras áreas, [...] a nossa atenção tem que se dar, primeiramente, na porta de entrada [...]". (E3)

Todavia, corroborando o verificado pelos entrevistados, estudos mostram que a formação demasiadamente voltada ao esporte ainda se faz presente nos dias atuais (Souza, Loch, 2011; Pasquim, 2010).

Costa et al. (2012), ao avaliarem as grades curriculares de 61 graduações em EF, observaram que a maioria não abordava conteúdos referentes à Saúde Coletiva/Saúde Pública. Também reconhecendo essa carência, Loch et al. (2011) indicaram a formação como o principal fator a ser discutido para uma melhor integração do PEF ao contexto da Saúde Pública.

Por ser um campo novo, a inserção do PEF na Saúde Pública foi identificada como um incentivo às mudanças na formação em $\mathrm{EF}$, a fim de torná-la qualificada para a área.

“[...] para trabalhar na área da Saúde Pública tem que ter uma formação para além da que eu tive, porque é muita construção que a gente vai ter que enfrentar. Um território totalmente novo. E acredito que vai levar certo tempo pra chegar ao que a gente idealiza hoje $[\ldots]^{\prime \prime} .(G F 1)$

Tendo em vista a ampliação dos campos de atuação profissional e as mudanças ocorridas no sistema de saúde vigente, Santos e Benedetti (2012), bem como Costa et al. (2012), ressaltaram a necessidade de as IES repensarem suas estruturas curriculares.

Costa et al. (2012) afirmaram ainda que disciplinas relacionadas à Saúde Coletiva auxiliam na compreensão do sistema de saúde e apropriação do processo de trabalho e da realidade das comunidades, possibilitando aumento da resolubilidade das ações dos PEF.

Os sujeitos da pesquisa avaliaram sua formação como insuficiente para a inserção na APS, e acreditam que, mesmo com as alterações já estabelecidas, os recém-formados também terão dificuldades.

“[...] não houve uma preparação pra que isso acontecesse, [...] a gente caiu de paraquedas na atenção primária, [...] a gente não tinha orientação nenhuma de como seria o trabalho, o que a saúde precisava pra gente tá atuando [...]". (GF2)

“[...] o primeiro concurso da secretaria de saúde, o qual contemplou vagas para a Educação Física, os estudantes precisaram fazer um cursinho fora, exatamente pelo fato deles não terem uma formação específica para essa área [...]". (E3)

Resultados semelhantes foram encontrados por outros estudos. Souza e Loch (2011) observaram que a maioria dos PEF afirmou ter tido uma graduação centrada no esporte, ou que não havia uma aproximação com a área da Saúde Pública. Do mesmo modo, Freitas (2007) constatou que o modelo de 
formação em EF tem privilegiado o trabalho individual e o espaço privado. Já Pasquim (2010) afirma que as graduações em EF que apresentaram disciplinas na área da Saúde Coletiva parecem não ser suficientemente estruturadas para produzir superações curriculares que permitam o desenvolvimento de uma formação densa na área.

Os entrevistados identificaram que a tradicional inserção do PEF no setor privado faz com que posturas e concepções advindas desse campo sejam reproduzidas também no setor público, o que impulsiona o aprendizado quanto ao último na prática do serviço. Entretanto, acreditam que essa condição seja inadmissível atualmente, já que percebem que o sistema público de saúde está mais exigente em relação aos profissionais admitidos em seu contexto.

“[...] atuava dessa forma, de achar que a atividade física é só incumbência minha, [...] a gente trouxe a visão do outro mercado. Vejo isso muito dentro do setor privado, que as coisas são fracionadas. [...] trouxe muito pelo motivo da gente não ter tido [...] essa formação enquanto graduação [...]". (GF1)

“[...] a maioria de nós aprendeu muito na prática, enfrentando as dificuldades e aprendendo dentro do processo. [...] a rede hoje, acredito que ela seja menos paciente do que foi conosco no momento que nos inserimos, porque era uma coisa nova, [...] agora algumas coisas já estão muito bem construídas [...]". (GF1)

Afirmaram também que a formação do PEF é biologicista e insuficiente para a atuação na APS.

“[...] a gente vem com a visão biologicista da atividade física, [...], se vamos trabalhar com saúde, eu vejo que só essa visão ela é pequena perto do que a gente deveria pensar e estar pronto a fazer. [...] é preciso que tenha uma capacitação, que tenha talvez alguma especialização, alguma coisa que prepare melhor esse profissional [...]". (GF1)

A formação biologicista do PEF pode ser justificada em virtude de sua história com a área médica, o que o fez se apropriar, de forma geral, do conceito de saúde como ausência de doença (Freitas, 2007).

A relação da formação da EF com a base biológica foi também evidenciada por Brugnerotto e Simões (2009), ao concluírem que a concepção de saúde dos planos de ensino de graduações em EF no Paraná é norteada pelo modelo biomédico, em que ficou claro que compete, ao PEF, avaliar, prescrever e monitorar programas de atividade física através de bases biológicas. Pasquim (2010), por sua vez, ressaltou a tendência da formação biologicista da EF ao afirmar que a atuação do PEF, se não está ligada diretamente à clínica e ao doente, está em função deles.

Anjos e Duarte (2009) acreditam que o ensino em saúde para a APS deva ser dirigido não apenas aos aspectos biológicos, mas, também, ao seu contexto e relações, numa abordagem integral. Para elas, a identificação de novas demandas em saúde possibilitaria a contextualização das ações do PEF.

Os depoentes identificaram as mudanças ocorridas na formação, para propiciar a atuação do PEF na Saúde Pública, como estratégias complementares, efetivadas por meio de disciplinas optativas. Dado semelhante foi percebido por Pasquim (2010) ao evidenciar a marginalização da temática Saúde Pública/ Saúde Coletiva nas graduações em EF.

"[...] aqui no curso de Educação Física diurno, nós temos algumas disciplinas optativas que têm esse olhar, não temos disciplinas obrigatórias [...]". (E3)

“O curso bacharelado noturno, [...] que vai ter início, [...] tem [...] numa formação complementar, não na grade básica, [...] [disciplina] focada na atenção primária [...]". (E3)

A estruturação do curso de EF em licenciatura e bacharelado é considerada uma alternativa para melhor caracterizar o campo de intervenção de cada habilitação e melhor definir as competências e 
saberes de cada eixo (Nunes, Votre, Santos, 2012; Souza, Loch, 2011). Contudo, os entrevistados acreditam que esta separação fez com que o bacharel perdesse a essência humanista, prejudicando sua atuação, sobretudo no que concerne ao cuidado integral.

Dado semelhante foi encontrado por Brugnerotto e Simões (2009), ao observarem que o enfoque humanista da saúde, quando abordado, ocorre nos cursos de licenciatura; e por Pasquim (2010), ao afirmar que a separação dos conteúdos da EF desfavorece a prática integral do PEF. No entanto, a expectativa é de que os conteúdos relacionados à Saúde Pública sejam aprofundados com o bacharelado (Souza, Loch, 2011).

No caso das experiências dos informantes-chave, a reestruturação da formação inicial do PEF foi citada por todos como fundamental para uma atuação exitosa na APS.

Para Guimarães e Silva (2010), rever a formação em saúde é pensar no desenvolvimento de competências específicas para a atuação na Saúde Pública, incentivando, no profissional, a capacidade de: avaliar, criticar, interagir, integrar e reformular suas práticas, considerando a diversidade dos indivíduos e das coletividades. Já para Brugnerotto e Simões (2009), repensar a formação é refletir sobre o real sentido da EF na promoção da saúde.

Para os entrevistados, o mercado de trabalho almeja profissionais de saúde com uma formação mais ampla, reforçando, portanto, a necessidade de uma formação que amplie a visão do PEF quanto à saúde, abrangendo indivíduos hígidos e doentes.
"[...] a formação tem que abrir mais o leque, [...] se o profissional não tiver uma formação ampliada nesse conteúdo multidisciplinar, [...] ainda vai ser muito deficitário [...]". (GF1)
“O Profissional de Educação Física [deve] começar a conhecer um pouco mais de doença. É um paradoxo, a gente tá falando de saúde, atenção primária, mas, até então, a gente não trabalhava com essas questões, [...] trabalhava [...] com a preparação física, com treinamento esportivo, com escola [...]". (E3)

No entanto, o PEF não conseguirá interferir no processo saúde-doença se sua formação e atuação forem alheias ao que diz respeito à dimensão coletiva, pública e social do mesmo (Anjos, Duarte, 2009).

Assim, acredita-se que sejam necessárias alterações na estrutura dos projetos político-pedagógicos e dos planos de ensino das graduações em EF. Tais alterações devem ofertar maiores oportunidades de estágio no contexto da APS, disciplinas específicas à área e/ou que a Saúde Pública seja tema transversal na grade curricular dos cursos.

“[...] hoje a educação e a saúde, elas têm que estar caminhando muito juntas, [...] não só de ter as matérias específicas, isso aí é evidente, [...] é o que tá faltando, mas, além disso, ainda ter o foco mesmo de formar, bater na tecla da saúde todo dia com eles". (GF2)

Costa et al. (2012) também acreditam que disciplinas relacionadas à Saúde Pública, nas graduações em EF, podem favorecer um despertar para essa área de atuação. Além disso, a sua carência tem feito com que muitos dos PEF se sintam incapazes de atuar na área e, por vezes, não reconheçam esse campo como de sua competência (Anjos, Duarte, 2009).

Brugnerotto e Simões (2009), ao analisarem currículos de cursos de EF, observaram que, a despeito de existirem temas afeitos à Saúde Coletiva, o enfoque ainda é predominantemente biológico, o que leva os autores a acreditarem na insuficiência de apenas criar disciplinas específicas. Para Pasquim (2010), o ideal é que não fosse necessária a criação de disciplinas específicas, mas que toda a formação tivesse a Saúde Coletiva como campo de atuação.

Quanto aos estágios, eles foram considerados, pelos entrevistados, como uma importante ferramenta para promover o desenvolvimento profissional, aproximando a teoria da prática e facilitando a inserção do recém-egresso na APS. Anjos e Duarte (2009) observaram a ausência de estágios da EF na APS e 
asseguram que a falta de convívio com a realidade do serviço desfavorece a prática naquele ambiente. Já Santos e Benedetti (2012) afirmam que o estágio contribui, efetivamente, na qualificação profissional e na melhor assistência às necessidades da população, o que favoreceria a inserção do PEF na APS.

Os depoentes também destacaram a necessidade de discussão interdisciplinar e trabalho interprofissional na graduação através de disciplinas integradas, de forma a incentivar o trabalho em equipe.

“[...] essa discussão interdisciplinar deveria ser trabalhada melhor nas universidades [...]. Fazer disciplinas integradas [...]. Chega lá na unidade de saúde tá todo mundo misturado, todo mundo tem que trabalhar junto, e na faculdade tá todo mundo trabalhando na sua salinha, na sua disciplina isoladamente $[\ldots . .]$.$" (GF2)$

Para Pasquim (2010), a inexistência do contato com outros cursos de graduação em saúde produz um empobrecimento do processo de formação, que, por consequência, não orienta os acadêmicos da $\mathrm{EF}$ para uma atuação em equipe multidisciplinar.

Foi ressaltada a necessidade de capacitação dos docentes, bem como a contratação de outros já com formação para a área da APS.

“[...] se o professor universitário não buscar se capacitar com esse olhar voltado pra saúde, não adianta mudar grade curricular porque ele vai continuar repetindo a sua formação, [...] a musculação vai ser musculação, a ginástica vai ser ginástica e a saúde vai continuar sendo separada [...]". (GF2)

Para eles, as DCN para o curso de graduação em EF não preveem a inserção do PEF na APS ou são insuficientes para a mesma.

“[...] elas não previam, e não preveem, até então, a inserção do Profissional de Educação Física na APS". (E3)

"[...] a mudança curricular [...] tem que ser muito mais complexa [...]". (GF1)

As diretrizes pressupõem a atuação do PEF em espaços públicos e em equipes multiprofissionais, e definem que o egresso deve ser responsável pela prevenção, promoção, proteção e reabilitação da saúde (Brasil, 2004). No entanto, para Pasquim (2010), esta afirmativa surge, aparentemente, apenas como reserva de mercado, buscando garantir um espaço no SUS e não impondo, a princípio, nenhuma alteração em sua intervenção ou formação profissional.

Os entrevistados defenderam que uma formação satisfatória para a APS favoreceria uma atuação mais segura, com maior clareza do papel do PEF, facilitaria a abordagem de alguns grupos de risco e melhoraria a relação na equipe.

Em consonância com essa afirmação, alguns autores alegam que a formação inicial adequada contribuiria, ainda, para a redução das dificuldades atuais de inserção e para a consolidação da profissão neste novo campo de intervenção; aumentaria o conhecimento sobre sistema e serviços de saúde, e incentivaria a admissão do PEF em cursos de pós-graduação em Saúde Coletiva, aumentando o número e a qualidade das pesquisas e publicações envolvendo sua atuação no SUS e potencializando sua abordagem neste campo (Costa et al., 2012; Pasquim, 2010; Anjos, Duarte, 2009).

\section{Formação continuada}

Os entrevistados reconhecem a formação pós-graduada como uma estratégia para o desenvolvimento profissional neste campo e, também, como uma forma de minimizar a defasagem da graduação. 
"[...] se na graduação ainda não se consegue dar uma informação e uma formação mais acentuada na área de saúde, na especialização que isso seja feito [...]". (E1)

Apesar de enxergarem a pós-graduação como uma forma de suprir a deficiência da graduação, Costa et al. (2012) afirmam que a aproximação deficiente da formação inicial a temas relacionados à Saúde Pública pode acarretar em uma baixa inserção do PEF nos programas de pós-graduação com essa abordagem.

A procura pelo CEABSF se deu pela necessidade, dos entrevistados, de incorporarem conhecimentos da APS e, consequentemente, melhorarem a sua atuação na área.

"[...] a gente veio [...] com essa sede de conhecimento, querendo entender como é que funcionava, buscando uma direção pro nosso trabalho, pra esclarecer todas as nossas dúvidas, [...] as nossas dificuldades e [...] entender qual a função da Educação Física na Saúde da Família [...]". (GF2)

Já a admissão do PEF no CEABSF foi motivada: pela inserção deste profissional na equipe do NASF, pela necessidade de que os mesmos tivessem uma formação voltada para a APS, e pelo interesse manifestado pelo CREF6/MG.

“[...] houve várias circunstâncias, uma era essa aspiração pra Educação Física ter uma formação na área da saúde e ligada à questão da saúde da família, a outra foi uma manifestação do Conselho Regional de Educação Física, que também queria que a gente fizesse $[\ldots] " . .(E 2)$

O CEABSF foi avaliado como um importante instrumento de formação do PEF para a APS, fornecendo a abertura de seu campo de trabalho através do conhecimento sobre o SUS e APS, e da apropriação do papel e importância da EF neste contexto.

Outro importante ganho mencionado a partir do conhecimento obtido no CEABSF foi o aumento da confiança para o trabalho, o que influenciou, positivamente, o relacionamento com os demais profissionais e no trabalho em equipe.

“[...] ter uma visão geral, uma visão da rede, uma visão dos campos que ele tem de estar atuando, [...] uma visão dos outros profissionais, essa integração, [...] da importância que tem o Profissional de Educação Física pra área da saúde, para melhora da qualidade de vida das pessoas". (GF1)

“[...] abre o campo de trabalho, [...] mas um campo de trabalho a partir de uma questão ética, ético-profissional, que é saber para trabalhar [...]". (E1)

"[...] foi onde eu comecei a me relacionar, que eu comecei a me sentir melhor pra trabalhar na saúde primária $[\ldots]^{\prime \prime} .(\mathrm{GF2})$

Entretanto, apontam a existência de dificuldades em acompanhar uma especialização que envolve um campo de atuação novo para este profissional, ainda pouco explorado nas graduações.

"[...] foi um choque de pegar tanta informação num curso de especialização". (GF2)

Creem também que a possibilidade de uma especialização com turma específica, como a Turma Épsilon do CEABSF, é importante para o atual momento da EF. Esta afirmativa foi comum nos grupos, mesmo acreditando que seria mais enriquecedora a participação em uma turma multiprofissional. 
"[...] seria muito mais efetivo se fosse uma turma multidisciplinar, mas [...] enquanto a Educação Física não tiver transformada, as turmas vão ter que ser só de Profissionais de Educação Física [...]. A gente tem que começar do básico [...], porque a gente não teve nada disso na faculdade, [...] o dia que o Profissional de Educação Física tiver uma formação comparável com a do enfermeiro, com a do odontólogo, com a do nutricionista, aí sim [...]". (GF2)

Desta forma, sugeriu-se que, futuramente, as turmas fossem de composição multiprofissional, vendo, nesse novo arranjo, um importante espaço para trocas de experiências, informações e habilidades.

“[...] seria interessante [...] essa especialização integrada com as outras profissões, porque eu vejo na minha equipe que eles têm mais dificuldade de atender a população, de falar a língua dessas pessoas. A população, muitas vezes, aproxima mais da gente, [...] a gente tem muito conhecimento pra passar pra eles também [...]". (GF2)

Os resultados da Turma Épsilon são aguardados com ansiedade, uma vez que há interesse em ampliar esta estratégia para todo o território nacional.

“[...] outros Conselhos Regionais de Educação Física no Brasil, e também o Conselho Federal de Educação Física, têm esperado com muita avidez como que será o término da primeira turma pra que esse modelo possa ser replicado no Brasil [...]". (E1)

\section{Considerações finais}

O estudo demonstrou que a inserção do PEF na APS é vista como um caminho novo, pavimentado por perspectivas positivas no que se refere à sua atuação e integração na equipe de saúde, com reflexos também positivos nos serviços e na comunidade.

Contudo, identificou-se que essa inserção acarreta desafios, o que faz com que o PEF passe por dificuldades de diferentes matizes, como: a frágil relação interprofissional, infraestrutura inadequada e, dentre outras, com destaque, a frágil formação para a APS.

A superação das limitações de sua formação inicial dar-se-á, entre outras questões, pelo estabelecimento de estratégias que contribuam para a integração qualificada do PEF na APS, tais como as sugeridas neste trabalho: reestruturação curricular, maiores oportunidades de aproximação da realidade através de estágios, transversalidade do tema na grade curricular, e interação com outras áreas do conhecimento através de disciplinas integradas.

A formação pós-graduada foi ressaltada, por todos os entrevistados, como uma estratégia positiva, no sentido de subsidiar os profissionais já inseridos no mercado de trabalho. Seu enfoque multidisciplinar foi ressaltado como necessário para a formação dos profissionais da APS.

No que diz respeito ao CEABSF, a parceria estabelecida entre as diversas instâncias da UFMG e o CREF6/MG demonstra o pioneirismo e a positividade da iniciativa. Assim, acredita-se que a mesma deva ser não só continuada, mas, também, expandida, o que poderá resultar em profissionais mais preparados para a APS e uma consequente abertura de mercado aos mesmos.

Desta forma, para que a inserção do PEF na APS se dê conforme preconizado pelos princípios e diretrizes do SUS, acredita-se que a formação deste profissional deva ser construída continuamente, levando em consideração a perspectiva dos atores envolvidos, o que neste trabalho indicou a necessidade de mudanças na formação inicial para que a EF possa assumir, de forma consciente e qualificada, esse campo de atuação.

Por se tratar de um estudo de caso, esta pesquisa não permite generalizações de seus resultados, porém, espera-se contribuir para avanços na discussão do tema e no despertar para novos estudos. 


\section{Colaboradores}

As autoras trabalharam juntas em todas as etapas de produção do manuscrito.

\section{Referências}

ANJOS, T.C.; DUARTE, A.C.G.O. A Educação Física e a Estratégia de Saúde da Família: formação e atuação profissional. Physis, v.19, n.4, p.1127-44, 2009.

BARDIN, L. Análise de conteúdo. 4.ed. Lisboa: Edições 70, 2008.

BONFIM, M.R.; COSTA, J.L.R.; MONTEIRO, H.L. Ações de Educação Física na saúde coletiva brasileira: expectativas versus evidências. Rev. Bras. Ativ. Fis. Saude, v.17, n.3, p.167-73, 2012.

BRASIL. Ministério da Saúde. Portaria n. 719, de 07 de abril de 2011. Institui o Programa Academia da Saúde no âmbito do Sistema Único de Saúde. Brasília: MS, 2011 .

. Ministério da Saúde. Portaria n. 2.488, de 21 de outubro de 2011. Aprova a Política Nacional de Atenção Básica, estabelecendo a revisão de diretrizes e normas para a organização da Atenção Básica, para a Estratégia Saúde da Família (ESF) e o Programa de Agentes Comunitários de Saúde (PACS). Brasília: MS, 2011b.

. Ministério da Saúde. Portaria n. 154, de 24 de janeiro de 2008. Cria os Núcleos de Apoio à Saúde da Família - NASF. Brasília: MS, 2008.

Conselho Nacional de Educação. Resolução n. 7, de 31 de março, de 2004. Institui as Diretrizes Curriculares Nacionais para os cursos de graduação em Educação Física, em nível superior de graduação plena. Brasília: CNE, 2004.

BRUGNEROTTO, F.; SIMÕES, R. Caracterização dos currículos de formação profissional em Educação Física: um enfoque sobre saúde. Physis, v.19, n.1, p.149-72, 2009.

CARLINI-COTRIM, B. Potencialidades da técnica qualitativa grupo focal em investigações sobre abuso de substâncias. Rev. Saude Publica, v.30, n.3, p.285-93, 1996.

COSTA, L.C. et al. Formação profissional e produtividade em saúde coletiva do Profissional de Educação Física. Rev. Bras. Ativ. Fis. Saude, v.17, n.2, p.107-13, 2012.

FREITAS, F.F. A Educação Física no serviço público de saúde. São Paulo: Hucitec, 2007.

GUIMARÃES, D.A.; SILVA, E.S. Formação em ciências da saúde: diálogos em saúde coletiva e a educação para a cidadania. Cienc. Saude Colet., v.15, n.5, p.2551-62, 2010.

HALLAL, P.C. Promoção da atividade física no Brasil: uma questão que vai além da saúde pública. Cad. Saude Publica, v.27, n.4, p.620-1, 2011.

LOCH, M.R. et al. A saúde pública nos anais do Congresso Brasileiro de Atividade Física e Saúde (1997-2009): revisão sistemática. Rev. Bras. Ativ. Fis. Saude, v.16, n.2, p.162-7, 2011.

LOCH, M.R.; FLORINDO, A.A. A Educação Física e as residências multiprofissionais em saúde. Rev. Bras. Ativ. Fis. Saude, v.17, n.1, p.81-2, 2012.

NUNES, M.P.; VOTRE, S.J.; SANTOS, W. O profissional em Educação Física no Brasil: desafios e perspectivas no mundo do trabalho. Motriz, v.18, n.2, p.280-90, 2012.

PASQUIM, H.M. A Saúde Coletiva nos cursos de graduação em Educação Física. Saude Soc., v.19, n.1, p.193-200, 2010. 
PEDROSA, O.P.; LEAL, A.F. A inserção do profissional de Educação Física na estratégia de saúde da família em uma capital do norte do Brasil. Rev. Movimento, v.18, n.2, p.235-53, 2012.

SANTOS, S.F.S.; BENEDETTI, T.R.B. Cenário de implantação do Núcleo de Apoio à Saúde da Família e a inserção do profissional de Educação Física. Rev. Bras. Ativ. Fis. Saude, v.17, n.3, p.188-94, 2012.

SILVA, I.Z.Q.J.; TRAD, L.B. O trabalho em equipe no PSF: investigando a articulação técnica e a interação entre profissionais. Interface (Botucatu), v.9, n.16, p.25-38, 2005.

SOUZA, S.C.; LOCH, M.R. Intervenção do profissional de Educação Física nos Núcleos de Apoio à Saúde da Família em municípios do norte do Paraná. Rev. Bras. Ativ. Fis. Saude, v.16, n.1, p.5-10, 2011.

YIN, R.K. Estudo de caso: planejamento e métodos. 3.ed. Porto Alegre: Bookman, 2005

FALCI, D.M.; BELISÁRIO, S.A. La inserción del profesional de educación física en la atención primaria a la salud y los desafíos en su formación. Interface (Botucatu), v.17, n.47, p.885-99, out./dez. 2013.

La inserción del profesional de educación física en el NASF dejó clara la fragilidad de su formación para la atención primaria. Este artículo tiene el objetivo de analizar su formación para la inserción en este campo, en el Estado de Minas Gerais. Se trata de una investigación cualitativa y exploratoria, del tipo de estudio de caso. Los datos se obtuvieron utilizándose grupos focales. Los resultados señalaron esa inserción como positiva para la profesión y para los servicios de salud, pero mostraron algunas dificultades, entre ellas, la formación durante la graduación se mencionó como insuficiente para actuar en la atención primaria. El postgrado se identificó como una de las estrategias para minimizar esa insuficiencia.

Palabras clave: Educación y entrenamiento físico. Atención Primaria de Salud. Núcleo de Apoyo a la Salud de la Familia. Formación de recursos humanos. Salud de la Familia. 
